\title{
Optimal selection of medium or high cost schemes in cleaner production for dyestuff industry based on fuzzy analytic hierarchy process
}

\author{
Li Guo ${ }^{1, a}$, Beihai Zhou, ${ }^{1, b}$, Jian Li ${ }^{2, c}$, Qiang Lu, ${ }^{2, d}$ and Yumei Chen ${ }^{2, e}$ \\ ${ }^{1}$ Energy and Environmental Engineering School, University of Science and Technology Beijing, \\ Beijing 100083, China \\ ${ }^{2}$ Xuzhou Kedah Fine Chemicals Ltd., Xuzhou 221011, China; \\ a15201455662@163.com, bzhoubeihai@sina.com, ljxzkd@sina.com, duqiangda@sina.cn, \\ echenyumei82@126.com.
}

\begin{abstract}
Keywords: cleaner production (CP); dyestuff industry; fuzzy analytic hierarchy process (FAHP) Abstract. Dyestuff industry, a traditional industry with high pollution and high energy consumption, is an important field implementing Cleaner Production (CP) in China. From the dimensions of technology, economy and environment, a domestic well-known dyestuff company has made an optimal selection of medium/ high cost CP schemes based on Fuzzy Analytic Hierarchy Process (FAHP). A four-level evaluation framework has been structured with 3 standard indicators, 10 target indicators and 5 schemes relating to the characteristics of the dyestuff processing production. According to the evaluation result, the wash water recycling scheme of Product A (F01) is the optimal choice with notable environmental and economic benefits, which could save 23 thousand tons of water and 500 thousand yuan every year. Practices show that it is feasible and reliable to use FAHP method to select an optimal CP scheme for dyestuff industry.
\end{abstract}

\section{Introduction}

Dyestuff, in a close relationship with human life, has been widely used in textile [1], paints plastics, leather, photoelectric communication, food industry and other fields. However, dyestuff industry, a traditional industry with high pollution and high energy consumption, discharges a large amount of waste water, waste gas and solid wastes [2]. Since the 21 st century, global dye basic synthetic business has gradually transfered from the developed countries in Europe and the United States to Asian emerging markets, especially in India and China [3].Their semi-finished products and finished products output accounts for $80 \%$ of the world, which suggests that India and China have become global dyes production bases. The 13th Five-Year Plan has designed the construction of ecological civilization and Chinese government continues to strengthen the national requirements of environmental protection, which brings forward the higher request of energy-saving and emission-reduction in the dyestuff industries. In recent years, the Action Plan for Water Pollution Prevention and Control [4], released by the State Council, underlines the crackdown on industrial pollution. The document calls for the closure by the end of 2016 of small plants including paper, leather, printing and dyeing, dyestuff, coking, smelting, sulfur and arsenic smelting, refining, electroplating, pesticide and so on, which could make serious pollution to the water environment that fail to meet pollution control standards.

What's more, reaching the discharge standards of industrial three-wastes has become the key to business survival. During the period of 12th Five-Year Plan, there are two important approaches for the green transformation and sustainable development of the dyestuff industry $[2,5,6]$. They are speeding up the process of the reform of the cleaner production $(\mathrm{CP})$ technology and vigorously promoting the $\mathrm{CP}$ demonstration project [7]. Therefore, $\mathrm{CP}$ is an important way to realize the goal of saving energy, reducing consumption, reducing pollution and increasing efficiency [8]. Scientific and rational evaluation methods should be used in enterprises to screen out the optimal schemes with advanced application of technology, obvious economic benefits and environmental friendly coordination. So far, methods used in the selection of CP technology schemes contain Life Cycle Assessment(LCA) [9, 10], Data Envelopment Analysis(DEA) [11, 12], Analytic Hierarchy 
Process(AHP) [13], fuzzy comprehensive evaluation method [14, 15]. And fuzzy hierarchy analysis hierarchy process (FAHP) [16] is the combination of the AHP and fuzzy comprehensive evaluation, synthetically considering qualitative and quantitative factors, precise and fuzzy variables, subjective and objective elements. In particular, the FAHP method can adequately handle the inherent uncertainty and imprecision of the human decision-making process, which has irreplaceable advantages for business leaders to make decisons.

In this paper, a well-known dyestuff enterprise in China, has taken 5 major feasible medium/high cost schemes as the carrier in the $\mathrm{CP}$ audit for optimal selection. A four-level evaluation framework based on the FAHP method has been structured with 3 standard indicators, 10 target indicators and 5 schemes relating to the characteristics of the dyestuff processing production. Then, the dyestuff enterprise leaders would take the apporach to select an optimal medium/ high cost scheme, in order to speed up the $\mathrm{CP}$ implementation and promote its sustainable development. In addition, the enterprise has implemented the schemes according to the evaluation results by the FAHP method, which has achieved the desired effect. Thus, the FAHP method in CP evaluation methodology has been proven a scientific and reasonable way to help enterprise decision-makers assess the optimal choice of CP schemes.

\section{CP schemes for evaluation}

$\mathrm{K}$ dye enterprise is a famous vat dye manufacturer and a designated supplier of domestic military camouflage dyes. Compared with other cotton dyes, vat dyes have the advantages of excellent color fastness, resistance to chlorine and natural colors. It still has occupied a certain shares in the domestic market, even if it has complex process, low yield and serious pollution [17]. Under the dual pressures of the market share decline and the national environmental policy, the $\mathrm{K}$ dye enterprise has to seek its own road of sustainable development. So, it has actively carried out CP audit [18] work since April 2015. During the period of CP audit, 132 non/ low cost schemes and 25 medium/ high cost schemes have been put forward. Considering that the enterprise funds, technology and energy are limited, the $\mathrm{CP}$ audit team have selected 5 major feasible medium/high cost schemes for the sake of water, electricity and steam, waste management and operation management etc (see Table 1).

Table 1. The list of medium/high cost schemes.

\begin{tabular}{|c|c|c|c|c|c|}
\hline \multirow{2}{*}{$\begin{array}{l}\text { Scheme } \\
\text { number }\end{array}$} & \multirow{2}{*}{ Scheme name } & \multirow{2}{*}{ Scheme content } & \multicolumn{2}{|c|}{ Expected effect } & \multirow{2}{*}{$\begin{array}{l}\text { Estimated } \\
\text { investment } \\
\text { [yuan] }\end{array}$} \\
\hline & & & Environment & Economy & \\
\hline F01 & $\begin{array}{l}\text { Wash water } \\
\text { recycling scheme } \\
\text { of Product A }\end{array}$ & $\begin{array}{l}\text { Half the amount of } \\
\text { washing water in the filter } \\
\text { of product would be } \\
\text { recycled }\end{array}$ & $\begin{array}{l}\text { Save } 23 \text { thousand } \mathrm{t} / \mathrm{a} \\
\text { water and reduce the } \\
\text { COD emissions of } \\
\text { about } 20 \mathrm{t} / \mathrm{a}\end{array}$ & $\begin{array}{l}\text { Save } 500 \\
\text { thousand yuan/a }\end{array}$ & $\begin{array}{c}300 \\
\text { thousand }\end{array}$ \\
\hline F02 & $\begin{array}{l}\text { Air fan frequency } \\
\text { energy saving } \\
\text { scheme }\end{array}$ & $\begin{array}{l}\text { Conversions of startup } \\
\text { mode in } 6 \text { Roots blowers }\end{array}$ & $\begin{array}{l}\text { Save electricity about } \\
135 \text { thousand } \mathrm{kW} \cdot \mathrm{hr} / \mathrm{a}\end{array}$ & $\begin{array}{l}\text { Save } 135 \\
\text { thousand yuan/ a }\end{array}$ & 1.2 million \\
\hline F03 & $\begin{array}{l}\text { Alternative } \\
\text { scheme of MVR } \\
\text { evaporation } \\
\text { system }\end{array}$ & $\begin{array}{l}\text { Replace four-effect } \\
\text { evaporator with MVR } \\
\text { evaporation system in } \\
\text { Product B }\end{array}$ & $\begin{array}{l}\text { Reduce waste water } \\
\text { emission and decrease } \\
\text { steam consumption }\end{array}$ & $\begin{array}{l}\text { Save } 500 \\
\text { thousand yuan/ a }\end{array}$ & 1.3 million \\
\hline F04 & $\begin{array}{l}\text { Modification } \\
\text { scheme of sewage } \\
\text { treatment process }\end{array}$ & $\begin{array}{l}\text { Transform the original } \\
\text { neutralization system, add } \\
\text { PSB biochemical pool and } \\
\text { reform CASS pools }\end{array}$ & $\begin{array}{l}\text { Improve the operation } \\
\text { effect of sewage } \\
\text { treatment }\end{array}$ & $\begin{array}{l}\text { Production } \\
\text { capacity can be } \\
\text { greatly improved }\end{array}$ & 3.8 million \\
\hline F05 & $\begin{array}{l}\text { Production } \\
\text { management } \\
\text { scheme of ERP } \\
\text { system }\end{array}$ & $\begin{array}{l}\text { ERP system manage } \\
\text { production, purchasing, } \\
\text { finance, warehouse and } \\
\text { other departments }\end{array}$ & $\begin{array}{l}\text { Optimize business } \\
\text { process and improve } \\
\text { production plan }\end{array}$ & $\begin{array}{l}\text { Production } \\
\text { management } \\
\text { could be } \\
\text { improved }\end{array}$ & $\begin{array}{l}400 \\
\text { thousand }\end{array}$ \\
\hline
\end{tabular}




\section{Methodology}

FAHP evaluation approach. The AHP method is a decision-making tool used for solving complex problems with multiple criteria by determining their priorities [19]. Moreover, FAHP method combines fuzzy comprehensive evaluation model with the AHP method to address multi-criterion decision problems in the project. Qualitative and quantitative evaluation index were constructed by fuzzy consistent judgment matrix. The results of single-sort and whole-sort of indexes by the test have shown satisfactory consistency. Through calculation of each index weight set, comprehensive evaluation values of different feasible scheme provide decision makers theoretical basis to choose the optimal scheme, as the evaluation process [20] of FAHP method is shown in Fig.1.

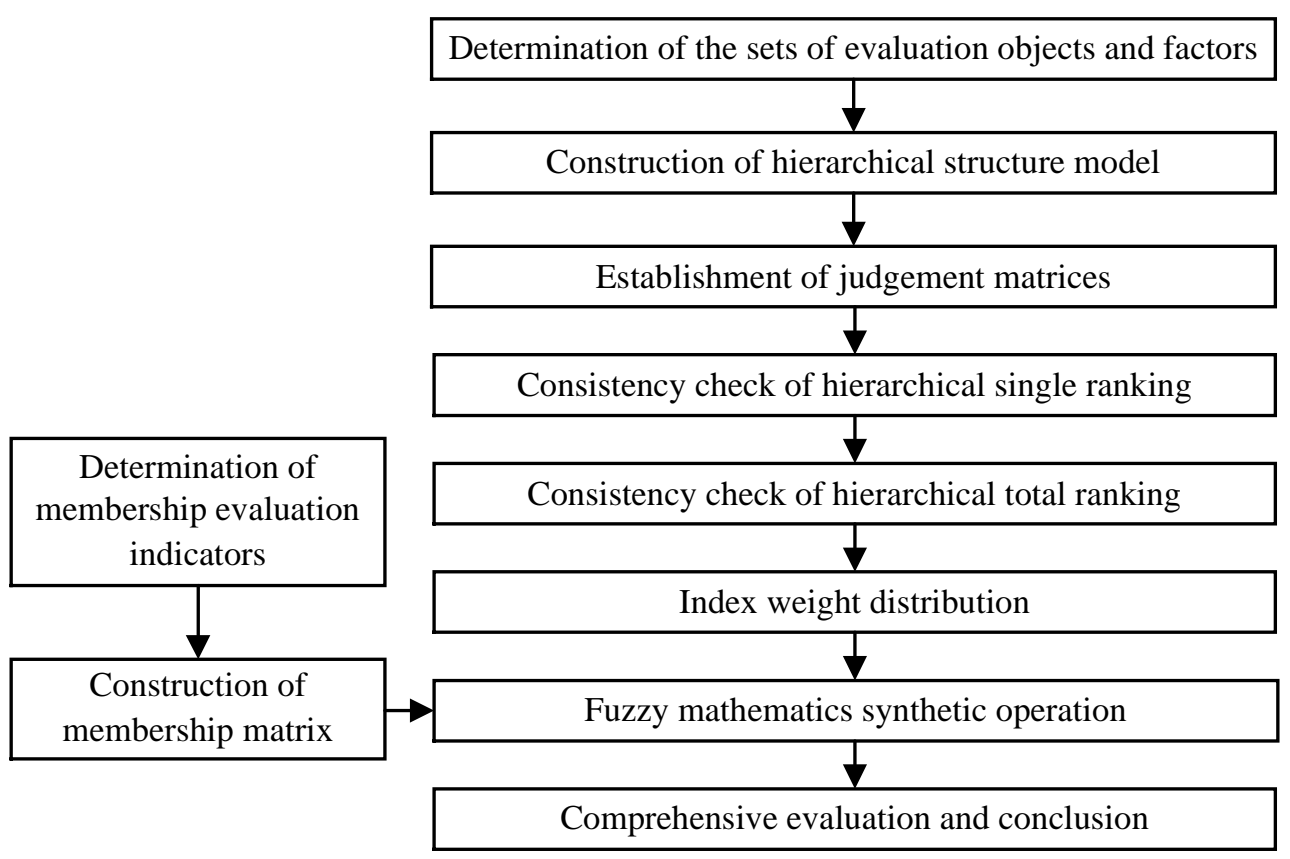

Fig.1. Flow chart of FAHP method.

Construction of the indicator framework and criteria. Through the FAHP method on the medium/ high cost CP schemes for scientific screening, the key step is to build a reasonable hierarchical structure model [21] based on the basic principles and procedures of AHP. The hierarchical structure consisted of 4 levels: the target layer, the standard layer, the index layer and the scheme layer, as shown in Fig.2. Given that the dyestuff industry doesn't have its own CP evaluation index, the construction of the indicator framework and criteria combined other industries' CP evaluation index system with $\mathrm{CP}$ audit requirements, mainly from three aspects of technical feasibility, economic feasibility and environmental feasibility, in order to establish the construction of the indicator framework and criteria. Taking the K dyestuff enterprise as a case, 5 feasible medium/ high cost schemes were evaluated here. 


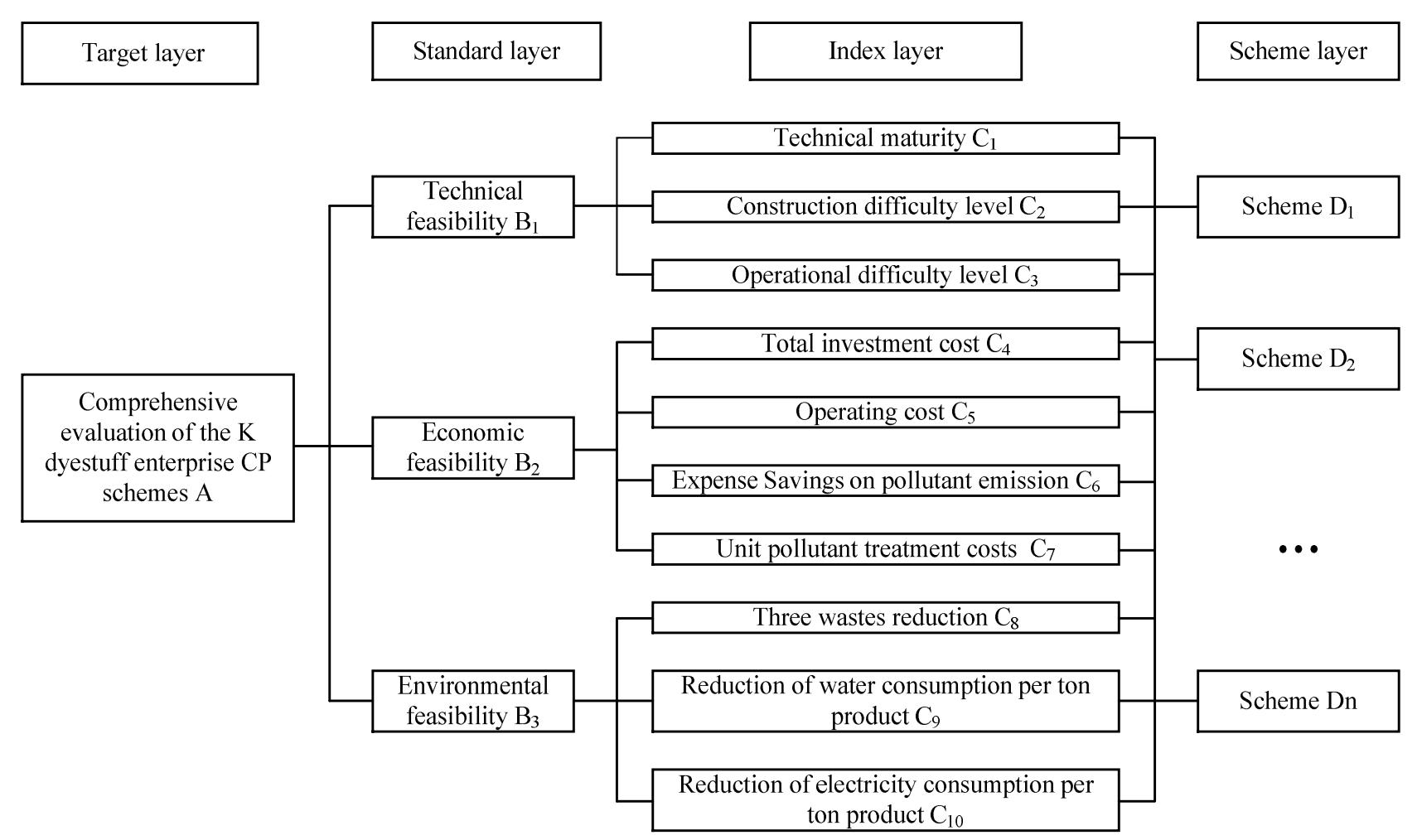

Fig.2. Hierarchical chart of cleaner production schemes in K dyestuff company.

Establishment of judgement matrices. The $\mathrm{K}$ dyestuff enterprise organized a expert group with 10 members, composed of board of directors, executives, environmental protection department, technology department, engineering department and municipal environmental science and technology department representatives. According to the 1-9 scale law [22] proposed by Professor Saaty, the expert group compared importance of pairwise indicators of the same level, and the results of judgment matrix in each level are shown as followed.

$$
\begin{aligned}
& \text { A-B judgement matrix: } R_{1}=\left[\begin{array}{ccc}
1 & 1 / 5 & 1 / 3 \\
5 & 1 & 3 \\
3 & 1 / 3 & 1
\end{array}\right] \\
& \mathrm{B}_{1}-\mathrm{C} \text { judgement matrix: } R_{2}=\left[\begin{array}{ccc}
1 & 3 & 2 \\
1 / 3 & 1 & 1 / 2 \\
1 / 2 & 2 & 1
\end{array}\right] \\
& \mathrm{B}_{2}-\mathrm{C} \text { judgement matrix: } R_{3}=\left[\begin{array}{cccc}
1 & 2 & 5 & 3 \\
1 / 2 & 1 & 3 & 2 \\
1 / 5 & 1 / 3 & 1 & 1 / 2 \\
1 / 3 & 1 / 2 & 2 & 1
\end{array}\right] \\
& \mathrm{B}_{3}-\mathrm{C} \text { judgement matrix: } R_{4}=\left[\begin{array}{cccc}
1 & 3 & 5 \\
1 / 3 & 1 & 2 \\
1 / 5 & 1 / 2 & 1
\end{array}\right]
\end{aligned}
$$

Index weight distribution. By the 4 judgment matrices, the importance value of the standard level and the weight of the index level were figure out through the classic calculation process of AHP method. And the specific calculation results are shown in Table 2. The indexes of B1 directly reflect the advanced degree of production technology and equipment of dyestuff industries. Then, the indexes of $\mathrm{B} 2$ are related to economical indicators that enterprise leaders pay more attention to. Moreover, The indexes of B3 are concerned with environmental issues, including industrial three wastes reducion, water consumption and so on. 
Table 2. The comprehensive distribution of index weight.

\begin{tabular}{lcccc}
\hline & \multicolumn{3}{c}{ Standard level B } & \\
\cline { 2 - 4 } Index level C & $\mathrm{B} 1$ & $\mathrm{~B} 2$ & $\mathrm{~B} 3$ & Weights \\
\cline { 2 - 4 } & 0.1067 & 0.6333 & 0.2600 & \\
\hline C1 & 0.5390 & & & 0.0575 \\
C2 & 0.1638 & & & 0.0175 \\
C3 & 0.2973 & & & 0.0317 \\
C4 & & 0.4824 & & 0.3055 \\
C5 & & 0.2718 & & 0.1721 \\
C6 & & 0.0883 & & 0.0559 \\
C7 & & 0.1575 & & 0.0998 \\
C8 & & & 0.6479 & 0.1685 \\
C9 & & & 0.2299 & 0.0598 \\
C10 & & & 0.1222 & 0.0318 \\
\hline
\end{tabular}

Consistency check. Because the judgment matrix is determined according to the experience of people, the result of analysis would be one-sided. The consistency of hierarchical ranking need to be checked, in case of the one sidedness. In the AHP law, the total consistency ratio $(C R)$ could be measured by the ratio of a consistency index $(C I)$ to a randomness index $(R I)$ :

\section{$C R=C I / R I$}

$$
C I=\left(\lambda_{\max }-n\right) /(n-1)
$$

where $\lambda_{\max }$ is the maximum eigenvalue of the matrix $\mathrm{A}, \mathrm{n}$ is the order of matrix $\mathrm{A}$. The $C R<0.1$ indicates a satisfactory degree of consistency in the corresponding comparison matrix, which means the judgment matrices pass the consistency test. Otherwise, the judgment matrices may not generate meaningful results for the failure of consistency test. $R I$ is average random consistency index, which can be found in Table 3. The hierarchical consistency test results of the 4 judgment matrix $\left(R_{1}, R_{2}, R_{3}\right.$, $R_{4}$ ) could be seen in Table 4 . The 4 judgment matrices passed the consistency check of hierarchical single ranking according to Table 4 , which means they do not need to be adjusted.

Table 3. The values of $R I$.

\begin{tabular}{cccccccccc}
\hline $\mathrm{n}$ & 1 & 2 & 3 & 4 & 5 & 6 & 7 & 8 & 9 \\
\hline$R I$ & 0 & 0 & 0.58 & 0.9 & 1.12 & 1.24 & 1.32 & 1.41 & 1.45 \\
\hline
\end{tabular}

Table 4. The results of consistency check.

\begin{tabular}{llll}
\hline Relationship & $\lambda \max$ & $C I$ & $C R$ \\
\hline A-B & 3.0388 & 0.0194 & 0.0335 \\
B $_{1}-\mathrm{C}$ & 3.0092 & 0.0046 & 0.0079 \\
$\mathrm{~B}_{2}-\mathrm{C}$ & 4.0178 & 0.0059 & 0.0066 \\
$\mathrm{~B}_{3}-\mathrm{C}$ & 3.0037 & 0.0018 & 0.0032 \\
\hline
\end{tabular}

Then, the consistency check of hierarchical total ranking was calculated by the following formula:

$$
R I \mathrm{c}=\sum_{\mathrm{j}=1}^{\mathrm{m} 1} a_{\mathrm{j}} * R I c_{\mathrm{j}}
$$




$$
R I \mathrm{c}=\sum_{\mathrm{j}=1}^{\mathrm{m} 1} a_{\mathrm{j}} * R I c_{\mathrm{j}}
$$

$C R \mathrm{c}=C T \mathrm{c} / R I \mathrm{c}$

From Table 2, Table 3 and Table 4 related data, we can find out the results of the total sequencing consistency check (See Table 5). As $C R \mathrm{c}=0.0060<0.10$ from Table 5, the hierarchical total ranking has passed the consistency test, which means the judgement matrices reach the requirements of a scientific and comprehensive evaluation used in the $\mathrm{K}$ dyestuff enterprise $\mathrm{CP}$ schemes selection.

Table 5. The result of total sequencing consistency check.

\begin{tabular}{|c|c|c|c|c|c|c|}
\hline \multirow{2}{*}{ Item } & \multicolumn{3}{|c|}{ Standard level B weights } & \multirow{2}{*}{ CIc } & \multirow{2}{*}{ RIc } & \multirow{2}{*}{$C R \mathrm{c}$} \\
\hline & B1 & B2 & B3 & & & \\
\hline Value & 0.1067 & 0.6333 & 0.2600 & 0.0047 & 0.7827 & 0.0060 \\
\hline
\end{tabular}

Construction of membership matrix. The expert group organized by the $\mathrm{K}$ dyestuff enterprise used Delphy method to score the 5 major feasible medium/ high cost schemes, for the sake of water, electricity and steam, waste management and operation management etc. Then the probability of the expert group's choice would be taken as the element of the membership degree. The evaluation comments are excellent, good, general and poor, while the membership statistics of 5 major schemes are shown in Table 6.

Table 6. The statistics of schemes' membership degree.

\begin{tabular}{|c|c|c|c|c|c|c|c|c|c|c|c|}
\hline \multirow{3}{*}{$\begin{array}{l}\text { Scheme } \\
\text { number }\end{array}$} & \multirow{3}{*}{ Degrees } & \multicolumn{10}{|c|}{ Membership evaluation indicators } \\
\hline & & $\mathrm{C} 1$ & $\mathrm{C} 2$ & $\mathrm{C} 3$ & $\mathrm{C} 4$ & $\mathrm{C} 5$ & C6 & $\mathrm{C} 7$ & $\mathrm{C} 8$ & C9 & $\mathrm{C} 10$ \\
\hline & & 0.0575 & 0.0175 & 0.0317 & 0.3055 & 0.1721 & 0.0559 & 0.0998 & 0.1685 & 0.0598 & 0.0318 \\
\hline \multirow{4}{*}{ F01 } & excellent & 0.9 & 0.8 & 0.9 & 0.9 & 0.9 & 0.4 & 0 & 0.4 & 0.8 & 0 \\
\hline & good & 0.1 & 0.2 & 0 & 0.1 & 0.1 & 0.4 & 0.1 & 0.2 & 0.2 & 0.4 \\
\hline & general & 0 & 0 & 0.1 & 0 & 0 & 0.2 & 0.5 & 0.4 & 0 & 0.4 \\
\hline & poor & 0 & 0 & 0 & 0 & 0 & 0 & 0.4 & 0 & 0 & 0.2 \\
\hline \multirow{4}{*}{ F02 } & excellent & 0.6 & 0.9 & 0.6 & 0.4 & 0.9 & 0 & 0 & 0.6 & 0 & 0.9 \\
\hline & good & 0.4 & 0.1 & 0.2 & 0.3 & 0.1 & 0 & 0 & 0.4 & 0.2 & 0.1 \\
\hline & general & 0 & 0 & 0.2 & 0.3 & 0 & 0.5 & 0.5 & 0 & 0.5 & 0 \\
\hline & poor & 0 & 0 & 0 & 0 & 0 & 0.5 & 0.5 & 0 & 0.3 & 0 \\
\hline \multirow{4}{*}{ F03 } & excellent & 0.8 & 0 & 0 & 0.4 & 0.6 & 0 & 0 & 0 & 0.8 & 0 \\
\hline & good & 0.1 & 0.2 & 0.2 & 0.3 & 0.4 & 0 & 0 & 0 & 0.2 & 0 \\
\hline & general & 0.1 & 0.4 & 0.5 & 0.3 & 0 & 0.8 & 0.5 & 0.8 & 0 & 0.5 \\
\hline & poor & 0 & 0.4 & 0.3 & 0 & 0 & 0.2 & 0.5 & 0.2 & 0 & 0.5 \\
\hline \multirow{4}{*}{ F04 } & excellent & 0.6 & 0 & 0 & 0 & 0.7 & 0.9 & 0.9 & 0.5 & 0 & 0 \\
\hline & good & 0.2 & 0.4 & 0.4 & 0.1 & 0.3 & 0.1 & 0 & 0.4 & 0.5 & 0.6 \\
\hline & general & 0.2 & 0.4 & 0.5 & 0.4 & 0 & 0 & 0.1 & 0.1 & 0.5 & 0.4 \\
\hline & poor & 0 & 0.2 & 0.1 & 0.5 & 0 & 0 & 0 & 0 & 0 & 0 \\
\hline \multirow{4}{*}{ F05 } & excellent & 0.1 & 0.9 & 0.1 & 0.8 & 0.8 & 0 & 0.1 & 0.2 & 0.1 & 0.1 \\
\hline & good & 0.6 & 0.1 & 0.2 & 0.2 & 0.1 & 0.5 & 0.6 & 0.5 & 0.2 & 0.4 \\
\hline & general & 0.3 & 0 & 0.5 & 0 & 0.1 & 0.4 & 0.1 & 0.3 & 0.4 & 0.4 \\
\hline & poor & 0 & 0 & 0.2 & 0 & 0 & 0.1 & 0.2 & 0 & 0.3 & 0.1 \\
\hline
\end{tabular}




\section{Empirical result}

Decision makers had a fuzzy comprehensive evaluation and picked up the maximum $B_{\mathrm{j}}(\mathrm{j}=1,2,3$, $4,5)$ by the principle of maximum membership grade. It generated the level of CP implementation corresponding to $\mathrm{B}_{\mathrm{j}}$ as the final evaluation result. The formula to calculate $B_{\mathrm{j}}$ is showed below:

$$
B=C \circ W
$$

Finally, the evaluation result of 5 major feasible medium/ high cost schemes has been made an order: F01, F02, F05, F04, F03, which means F01 is the most optimal scheme while F03 is the worst (see Table 7). Taking strategic objectives, capital turnover, production planning, personnel allocation and other factors into account, the $\mathrm{K}$ dyestuff enterprise have given priority to the implementation of the F01 scheme. Moreover, the other feasible schemes would be implemented at appropriate times.

Table 7. Fuzzy comprehensive assessment results of schemes.

\begin{tabular}{llllll}
\hline \multirow{2}{*}{$\begin{array}{l}\text { Scheme } \\
\text { number }\end{array}$} & \multicolumn{5}{c}{ Membership degree } \\
\cline { 2 - 5 } & excellent & good & general & $\begin{array}{l}\text { poo } \\
\text { r }\end{array}$ & \\
\hline F01 & 0.66 & 0.15 & 0.14 & 0.05 & 1 \\
F02 & 0.48 & 0.22 & 0.21 & 0.10 & 2 \\
F03 & 0.32 & 0.19 & 0.37 & 0.13 & 5 \\
F04 & 0.38 & 0.24 & 0.23 & 0.16 & 4 \\
F05 & 0.46 & 0.32 & 0.17 & 0.05 & 3 \\
\hline
\end{tabular}

The K dyestuff enterprise completed the wash water recycling scheme of Product A (F01) at the end of January 2016. Then, the workshop officially used the wash water recycling scheme in March 2016. The dye color, strength, yield, copper ion concentration and iron ion concentration of Product A were tested to ensure its product quality. Exhilaratingly, all test results were qualified and the water saving effect of F01 scheme was so obvious that it could save 23 thousand t/a water and reduce the COD emissions of about 20 t/a (see Table 8). What's more, the F01 scheme had notable economic benefits that it could save 500 thousand yuan /a for the enterprise. Since the cost of the F01 scheme is about 300 thousand yuan, it takes about 7 months to recover investment. Above all, it can provide a demonstration project of water-saving technological transformation for other products.

Table 8. Evaluation of Scheme F01's implementation effect.

\begin{tabular}{cccc}
\hline Comparison item & Unit & Before & After \\
\hline Dye strength & {$[\%]$} & 370 & 375 \\
Iron ion concentration & {$[\mathrm{mg} / \mathrm{g}]$} & 500 & 550 \\
Copper ion concentration & {$[\mathrm{mg} / \mathrm{g}]$} & 150 & 160 \\
Water consumption per unit product & {$[\mathrm{t} / \mathrm{t}]$} & 130 & 65 \\
Annual water consumption & {$[\mathrm{kt} / \mathrm{a}]$} & 46 & 23 \\
Total COD emission & {$[\mathrm{t} / \mathrm{a}]$} & 70 & 50 \\
\hline
\end{tabular}

\section{Conclusions}

In the process of selecting optimal medium/ high cost $\mathrm{CP}$ scheme in the dyestuff industry, a four-level evaluation framework was constructed with 3 standard indicators, 10 target indicators and 5 schemes relating to the dyestuff processing production. Based on the FAHP evaluation result, the K dyestuff enterprise has given priority to the implementation of the F01 scheme with notable environmental and economic benefits. The F01 scheme could save 23 thousand tons of water and 500 thousand yuan every year. Practice shows that the application of FAHP method for the dye industry in optimal selection of medium/high cost CP schemes is scientific and reliable. And the FAHP method 
can assist the enterprise leaders to make the decisions most conducive to the development of enterprises.

\section{Acknowledgements}

The authors are particularly grateful to Xuzhou Kedah Fine Chemicals Ltd. for funding support and anonymous industrial experts for engineering assistance.

\section{References}

[1] M. Gulmini, A. Idone, E. Diana, D. Gastaldi, D. Vaudan, M. Aceto. Dyes Pigments Vol. 98 (2013), p. 136

[2] Y. He, G. Li, J. Zhao, H. Su. Filtr Separat, Vol. 44 (2007), p. 22

[3] N. Terinte, B.M.K. Manda, J. Taylor, K.C. Schuster, M.K. Patel: Journal of Cleaner Production Vol. 72 (2014), p. 127

[4] S. Belayutham, V.A. González, T.W. Yiu: Journal of Cleaner Production Vol. 135(2016), p. 1363

[5] J. Long, H. Xu, C. Cui, X. Wei, F. Chen, A. Cheng: Journal of Cleaner Production Vol. 65 (2014), p. 574

[6] L. Hong, N. Zhou, D. Fridley, C. Raczkowski: Energ Policy Vol. 62 (2013), p. 1533

[7] H. Peng, Y. Liu: Journal of Cleaner Production Vol. 135 (2016), p. 1138

[8] J.J. Klemeš, P.S. Varbanov, S. Pierucci: Appl Therm Eng Vol. 30 (2010), p. 2265

[9] V.G. Lo-Iacono-Ferreira, J.I. Torregrosa-López, S.F. Capuz-Rizo: Journal of Cleaner Production Vol. 133 (2016), p. 43

[10]A. Petrillo, F. De Felice, E. Jannelli, C. Autorino, M. Minutillo, A.L. Lavadera: Renew Energ Vol. 95 (2016), p. 337

[11]M. Shwartz, Jr. J.F. Burgess, J. Zhu: Eur J Oper Res Vol. 253 (2016), p. 489

[12]B. Wu, Y. Wang, J. Zhang, E.E. Savan, X. Yan: Accident Analysis \& Prevention Vol. 81 (2015), p. 232

[13]V. Elia, M.G. Gnoni, A. Lanzilotto: Expert Syst Appl Vol. 63 (2016), p. 187

[14]Y. Wang, Y. Li, W. Liu, Y. Gao: Ocean Eng Vol. 107 (2015), p. 54

[15]P. Ghadimi, A.H. Azadnia, N.M. Yusof, M.Z.M. Saman: Journal of Cleaner Production Vol. 33 (2012), p. 10

[16]M. Tseng, Y. Lin, A.S.F. Chiu: Journal of Cleaner Production Vol. 17 (2009), p. 1249

[17]T. Bechtold, A. Turcanu: Journal of Cleaner Production Vol. 17 (2009), p. 1669

[18]J. Hong, X. Li: Journal of Cleaner Production Vol. 40 (2013), p. 129

[19]S. Bai, J. Zhang, Z. Wang: Journal of Cleaner Production Vol. 102 (2015), p. 461

[20]P. Manekar, T. Nandy, A. Sargaonkar, B. Rathi, M. Karthik: Bioresource Technol Vol. 102 (2011), p. 558

[21]D. Galvez, A. Rakotondranaivo, L. Morel, M. Camargo, M. Fick: J Manuf Syst Vol. 37 (2015), p. 616

[22]L. Li, Z. Shi, W. Yin, D. Zhu, S.L. Ng, C. Cai, A. Lei: Ecol Model Vol. 220 (2009), p. 3439 